\title{
Identifikasi Formalin pada Jajanan Siomay
}

\section{Identification of Formalin in Siomay Snacks}

\author{
FITRIANI KAHAR* \\ FERAWATI RONDONUWU**
}

\author{
Jurusan Kesehatan Masyarakat Universitas Pancasakti Makassar* \\ Jalan Serigala No. 01 Makassar \\ Jurusan Kesehatan Masyarakat Universitas Indonesia Timur Makassar** \\ Email:fitrianikahar888@gmail.com
}

\begin{abstract}
Abstrak
Formalin adalah larutan yang tidak berwarna dan baunya sangat menusuk, biasanya digunakan sebagai pengawet mayat. Pemberian bahan pengawet jenis formalin dilarang pada makanan, bahkan makanan yang mengandung formalin jika dikonsumsi secara terus menerus akan menimbulkan gejala keracunan, kanker (kanker hati) yang ditimbulkan secara tidak langsung. Tujuan penelitian tentang identifikasi formalin pada Siomay secara kualitatif yaitu untuk mengetahui ada tidaknya formalin dalam Siomay yang diambil di Kelurahan Tamamaung. Dari hasil identifikasi, 4 dari 5 (80\%) sampel tidak mengandung bahan pengawet jenis formalin, manfaat dari penelitian untuk melindungi masyarakat konsumen khususnya penggemar Siomay agar tetap aman dalam mengkonsumsi Siomay yang diperdagangkan di Kelurahan Tamamaung ini membuktikan bahwa adanya kesadaran pedagang dalam memproduksi makanan khususnya Siomay yang banyak digemari oleh masyarakat. Agar pemerintah atau tokoh masyarakat memberikan informasi kepada para pedagang dan pengusaha maupun konsumen terutama masyarakat umum di Kelurahan Tamamaung tentang bahaya penggunaan bahan pengawet jenis formalin, sehingga tidak menggunakan formalin sebagai bahan pengawet makanan.
\end{abstract}

Kata Kunci: Identifikasi Formalin ; Siomay

\begin{abstract}
Formalin is a colorless solution and smells very strong, usually used as a preservative of dead bodies. Provision of formalin preservatives is prohibited on food, even food containing formaldehyde if consumed continuously will cause symptoms of poisoning, cancer (liver cancer) which is caused indirectly. The purpose of research on identifying formaldehyde in Siomay qualitatively is to determine whether there is formaldehyde in Siomay taken in Tamamaung Village. From the identification results, 4 out of 5 (80\%) samples do not contain formalin preservatives, the benefits of research to protect the consumer community, especially Siomay fans to stay safe in consuming Siomay traded in Tamamaung Urban Village prove that there is awareness of traders in producing food especially Siomay is much favored by the community. So that the government or community leaders provide information to traders and entrepreneurs and consumers, especially the general public in Kelurahan Tamamaung about the dangers of using formalin preservatives, so that they do not use formalin as a food preservative.
\end{abstract}

Keyword: Formalin identification ; Siomay 


\section{Pendahuluan}

Beberapa kebutuhan manusia yang penting adalah pangan, sandang, pendidikan dan kesehatan. Masalah pangan selalu mendesak disamping cepatnya laju kenaikan penduduk. Dalam pencapaian sasaran pangan, selain tersedianya pangan yang cukup dalam jumlah, mutu berguna, merata, bergizi dan terjangkau oleh daya beli masyarakat, pangan tersebut juga harus aman untuk dikonsumsi sehingga menjamin terciptanya ketahanan dan keamanan pangan sesuai dengan Peraturan Pemerintah No 28 Tahun 2004 (Saparinto, C. 2006).

Peningkatan kualitas sumber daya manusia salah satunya ditentukan oleh kualitas pangan yang dikonsumsi. UUD No 7 Tahun 1996 mengatakan bahwa kualitas pangan yang dikonsumsi harus memenuhi beberapa kriteria, diantaranya adalah aman, bergizi, bermutu dan dapat terjangkau oleh daya beli masyarakat. Aman yang dimaksud di sini mencangkup bebas dari pencemaran biologis, mikrobiologis, kimia dan logam berat. Penggunaan pengawet pada bahan makanan sampai saat ini masih banyak dijumpai.

Salah satu bahan kimia berbahaya yang sering digunakan dalam pengawetan bahan pangan olahan adalah formalin. Beberapa bahan makanan seperti : tahu, bakso/siomay, mie basah, kerupuk, nugget, ikan kering, ikan laut yang lama waktu penangkapanya masih dijumpai menggunakan formalin sebagai bahan pengawet (Anonim, 1996). Patut kita cermati di sini, makanan tersebut, pasti membutuhkan bahan pengawet, karena untuk memproduksi produk-produk makanan tersebut dalam jumlah yang besar, tak mungkin jika tidak menggunakan bahan pengawet. Sebuah produk berpotensi bebas dari bahan pengawet, jika daya simpannya relatif singkat, yaitu berkisar antara tiga sampai empat hari. Memprihatinkan, pada beberapa bahan makanan masih ditemukan formalin yang digunakan sebagai pengawet.

Berkembangnya produk pangan awet terjadi karena semakin tingginya kebutuhan masyarakat terhadap berbagai jenis makanan yang awet dan praktis. Kebanyakan makanan yang dikemas mengandung bahan tambahan, suatu bahan yang dapat mengawetkan makanan atau merubahnya dengan berbagai teknik. Untuk membedakan mana produk makanan yang diawetkan dengan larutan formalin atau senyawa lainnya, apalagi perdagangan siomay yang meluas dimasyarakat dengan harga relatif murah kemudian mutu sensoris dapat diperkuat dengan pengujian fisik, kimiawi dan mikrobiologis yang tentu saja memerlukan teknik peralatan dan tenaga khusus yang tentunya tidak mudah dan tidak murah, paling tidak ada empat parameter sensoris utama yaitu penampakan warna, bau, rasa dan tekstur (Anonim, 2008).

Formalin adalah nama dangang formaldehida yang dilarutkan dalam air dengan kadar 36 - 40\%. Formalin merupakan salah satu pengawet yang dilarang digunakan untuk mengawetkan bahan makanan karena formalin biasanya digunakan sebagai pembunuh kuman atau pembasmi lalat, pengawet mayat dan berbagai jenis bahan industri non makanan. Formalin merupakan zat karsinogenik yang dapat menyebabkan kanker dan apabila terminum akan menyebabkan kematian. Penggunaan formalin dalam makanan sangat membahayakan konsumen. Tetapi faktanya masih ditemukan pengolah makanan yang menambahkan formalin sebagai pengawet makanan (Yuliarti 2007).

Produk pangan berformalin itu dijual di sejumlah pasar dan supermarket di wilayah DKI Jakarta, Banten, Bogor dan Bekasi. Adanya bahan aditif dan pengawet berbahaya dalam makanan ini sebenarnya sudah lama menjadi rahasia umum. Tetapi masalah klasik tersebut kembali menjadi pembicaraan hangat akhir tahun ini karena temuan Balai POM. Fakta ini lebih menyadarkan masyarakat bahwa selama ini terdapat bahaya formalin yang mengacam kesehatan yang berasal dari komsumsi makanan sehari-hari (Awang, 2006).

Siomay adalah daging cincang (dihaluskan) yang dicampur dengan tepung teringu dan kanji. Walaupun demikian, siomay juga dibuat dari udang, daging kepiting atau danging sapi. Siomay dibuat berbentuk bulat seperti bola bakso. Setelah dimatangkan dengan cara direbus, siomay dimakan dengan saos, lombok dan kecap manis.

Sampel (Siomay) yang mengandung bahan pengawet jenis formalin biasanya berwarna putih pucat, sangat kenyal, tidak busuk bila disimpan sampai 5 hari dan aromanya atau bauhnya menyengat pada saat dimasak. Penggunaan formalin dalam makanan dapat 
menyebabkan masalah kesehatan yakni gangguan pernapasan, sakit kepala dan kanker paru-paru sampai menyebabkan kematian (Cahyadi, 2008). Pada observasi pedagang somay yang berada di Kelurahan Tamamaung Kota Makassar biasanya somay yang dijual terlihat berwarna putih dan sangat kenyal sehingga dicurigai adanya formalin pada somay tersebut.

\section{Metode}

Penelitian ini adalah penelitian laboratorium dengan pendekatan deskriptif yang bertujuan untuk mengetahui ada tidaknya formalin pada siomay dengan metode Kualitatif (uji fenilhidrazin). Populasi dalam penelitian ini adalah semua penjual siomay yang berjualan di Kelurahan Tamamaung. Alat-alat yang digunakan dalam penelitian ini adalah seperangkat alat gelas dan alat destilasi. Bahan-bahan yang digunakan dalam penelitian ini adalah sampel siomay, pereaksi asam fosfat pekat $85 \%\left(\mathrm{H}_{3} \mathrm{PO}_{4}\right), \mathrm{K}_{3}\left(\mathrm{Fe}\left(\mathrm{CN}_{6}\right) 1 \%\right.$ (Kalium Feri Siamida), fenilhidrazin $1 \%$ dan Asam Klorida Pekat $(\mathrm{HCl})$, serta aquadest. Pemeriksaan sampel dilakukan di Balai Besar laboratorium Kesehatan (BBLK) Makassar.

\section{Hasil dan Pembahasan}

Hasil penelitian yang dilakukan di Balai Besar Laboratorium Kesehatan (BBLK) dapat dilihat dalam tabel sebagai berikut:

Tabel 1. Tabel Pemeriksaan Formalin Pada Pada Jajanan Siomay Yang Diperdagangkan di Kelurahan Tamamaung Kota Makassar

\begin{tabular}{cccc}
\hline \multirow{2}{*}{ No } & Kode & \multicolumn{2}{c}{ Hasil } \\
\cline { 3 - 4 } Sampel & Sampel & Keterangan \\
\hline 1 & $\mathrm{~A}$ & Kuning & Negatif (-) \\
2 & $\mathrm{~B}$ & Kuning & Negatif (-) \\
3 & $\mathrm{C}$ & Kuning & Negatif $(-)$ \\
4 & $\mathrm{D}$ & Kuning & Negatif $(-)$ \\
5 & $\mathrm{E}$ & Merah kuning & Positif $(+)$ \\
\hline
\end{tabular}

Data pada tabel 4.1 menunjukkan bahwa dari 5 sampel yang dilakukan pemeriksaan kandungan formalin pada siomay maka ditemukan hasil bahwa terdapat 1 sampel positif mengandung formalin dengan persentase $20 \%$ dan terdapat 4 sampel negatif mengandung formalin dengan persentase $8 \%$.

Gambar 1. Gambar Hasil Destilasi Sampel Pada Pemeriksaan Formalin Pada Pada Jajanan Siomay Yang Diperdagangkan di Kelurahan Tamamaung Kota Makassar

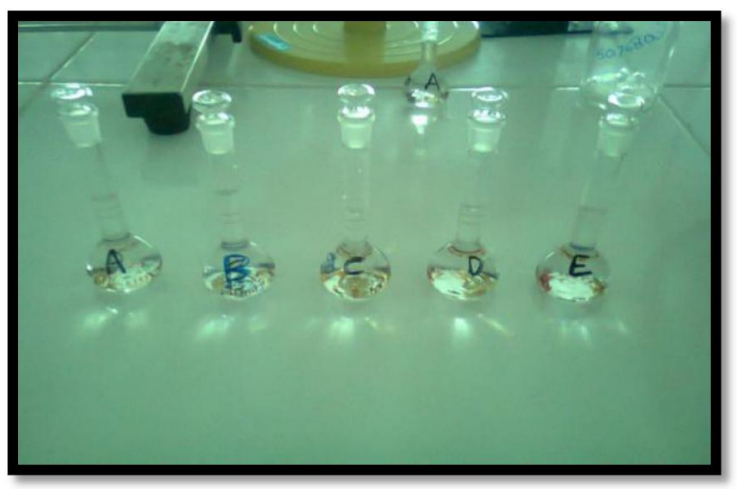


Pada gambar 1 menunjukkan hasil destilasi dari 5 sampel pemeriksaan formalin pada jajanan siomay yang diperdagangkan di Kelurahan Tamamaung Kota Makassar.

\section{Gambar 2. Gambar Hasil Pemeriksaan Formalin Pada Pada Jajanan Siomay Yang Diperdagangkan di Kelurahan Tamamaung Kota Makassar}

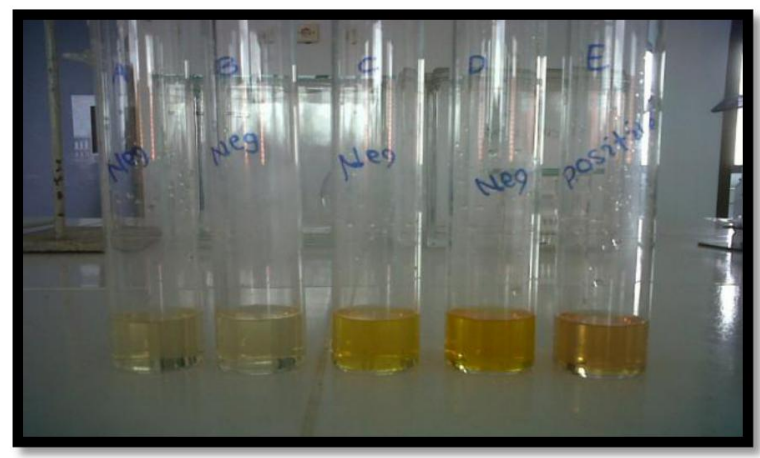

Pada gambar 2 menunjukkan hasil pemeriksaan formalin pada jajanan siomay yang diperdagangkan di Kelurahan Tamamaung Kota Makassar dari 5 sampel yang diperiksa. Hasil positif akan menunjukkan warna merah kuning, sedangkan hasil negatif akan berwarna kuning.

Dalam penelitian ini sampel yang digunakan adalah sampel siomay yang diperdagangkan di Kelurahan Tamamaung Kota Maakassar. Sampel tersebut diambil kemudian dilakukan penelitian di Balai Besar Laboratorium Kesehatan (BBLK) dengan tujuan yaitu untuk mengetahui ada tidaknya bahan pengawet jenis formalin dalam sampel tersebut dengan menggunakan metode uji fenilhidrazin. Sampel siomay yang diambil di Kelurahan Tamamaung Kota Makassar mempunyai warna yang berbeda, dimana siomay yang berwarna putih pucat mengandung bahan pengawet jenis formalin dibandingkan dengan siomay yang berwarna putih kecoklatan.

Sampel (Siomay) yang mengandung bahan pengawet jenis formalin biasanya sangat kenyal, tidak busuk bila disimpan sampai 5 hari dan aromanya atau bauhnya menyengat pada saat dimasak.Identifikasi formalin dilakukan dengan cara kualitatif dengan menggunakan pereaksi asam fosfat pekat $85 \%\left(\mathrm{H}_{3} \mathrm{PO}_{4}\right), \mathrm{K}_{3}\left(\mathrm{Fe}\left(\mathrm{CN}_{6}\right) \quad 1 \%\right.$ (Kalium Feri Siamida), fenilhidrazin $1 \%$ dan Asam Klorida Pekat $(\mathrm{HCl})$ yang bila positif maka terjadi perubahan warna kuning menjadi kemerah-merahan.

Hasil identifikasi formalin menunjukkan bahwa dari 5 sampel yang dilakukan pemeriksaan kandungan formalin pada siomay maka ditemukan hasil bahwa terdapat 1 sampel positif mengandung formalin dengan persentase $20 \%$ dan terdapat 4 sampel negatif mengandung formalin dengan persentase $8 \%$. Hal ini menunjukkan adanya resiko bahaya kesehatan pada masyarakat karena ditemukan sampel yang positif. Penggunaan formalin dalam makanan dapat menyebabkan masalah kesehatan yakni gangguan pernapasan, sakit kepala dan kanker paru-paru sampai menyebabkan kematian

Hal ini dikarenakan tingkat kesadaran pedagang atau pengusaha makanan dalam menjaga keamanan makanan kurang baik. Jika makanan kita mengandung bahan pengawet jenis formalin dalam jangka waktu pendek tidak akan mengalami keracunan, akan tetapi setelah makanan yang mengandung bahan pengawet jenis formalin tersebut selalu dikonsumsi maka akan berubah sifatnya menjadi karsinogen yang dapat merangsang terjadinya kanker hati.

\section{Simpulan dan Saran}

\section{Simpulan}

Berdasarkan hasil penelitian dan pembahasan diatas maka dapat disimpulkan bahwa dari 5 sampel yang diperiksa terdapat 1 sampel positif mengandung formalin dengan persentase 
$20 \%$ dan terdapat 4 sampel negatif mengandung formalin dengan persentase $8 \%$. Maka siomay yang diperdagangkan di Kelurahan Tamamaung Kota Makassar tidak menggunakan bahan pengawet jenis formalin. Hal ini disebabkan karena tingkat kesadaran dan pengetahuan pengusaha dan pedagang tersebut tentang bahaya penggunaan bahan tambahan pangan jenis formalin belum sepenuhnya.

\section{Saran}

Agar pemerintah dalam hal ini dinas kesehatan provinsi mempunyai peran aktif melakukan sosial mengenai dampak terhadap penggunaan formalin, atau tokoh masyarakat memberikan informasi kepada para pedagang dan pengusaha maupun konsumen terutama masyarakat umum di Kelurahan Tamamaung Kota Makassar tentang bahaya peggunaan bahan pengawet jenis formalin, sehingga tidak menggunakan formalin sebagai bahan pengawet makanan. Dengan demikian konsumen siomay khususnya di Kelurahan Tamamaung akan menjadi lebih aman terhadap dampak penggunaan bahan pengawet jenis formalin.

Kepada peneliti yang berminat meneliti lebih jauh tentang siomay, agar meneliti bahan pengawet lain yang terdapat pada siomay.

\section{Daftar Pustaka}

Anonim, 1979. Farmakope Indonesia Edisi III Jakarta: Departemen Kesehatan RI (hal : 259) Anonim. 1998. Peraturan Menteri Kesehatan No.722 Tahun 1988 Tentang Bahan Tambahan Makanan. Jakarta.

Anonim, 1999. Peraturan Kesehatan Menteri RI Nomor 1168/MENKES/PER/X/1999 Tentang Perubahan atas Peraturan Menteri Kesehatan No.722/MENKES/PER/XI/1988 Tentang Bahan Tambahan Makanan. Jakarta.

Anonim, 2008. "Ilmu Pangan Bahan Tambahan Pangan". www.ilmupangan.com2008

Anonim, 2009. http://putrairawan. Wordpress.com/2009/03/05/formalin/.

Abdullah. 2011. Pengawetan Pangan. UI Press. Jakarta.

Alsuhendra dan Ridawati. 2013. Bahan Toksik dalam Makanan. Rosda. Jakarta

Awang. 2006. Kesehatan Pengawet Dalam Makanan. Pusat Racun Negara. USM

Cahyadi, W. 2008. Analisis dan aspek kesehatan bahan tambahan pangan Edisi 2 Cetakan I. Jakarta : Bumi Aksara.

Desrosier. R. W, 1988. Teknologi Pengawet Pangan. Edisi III.

Efendy. 2004. Penggunaan Bahan Tambahan Makanan. Media Indonesia. Jakarta.

Hastuti, S. 2010. Analisis kualitatif dan kuantitatif formaldehid pada ikan asin di Madura..Jurnal Agrointek. Vol 4, No. 2 Agustus 2010 Hal 132-137.

Saparinto, C. 2006. "Food Additives" Amankah Bagi Kita? Kumpulan dan Gagasan Tertulis 1978 - 1981. Pusat Penelitian dan Pengembangan Teknologi Pangan. Institut Pertanian Bogor.

Saparitno, C dan Hidayati, D. (2006). Bahan tambahan pangan. Kanisius. Yogyakarta.

Wispriyono. 2006. Formalin. Penerbit Trubus Agrisarana. Surabaya.

Yayuk. K. B. 1987 “Ilmu Pangan”Universitas Indonesia. Jakarta.

Yuliarti N. 2007. Awasi bahaya dibalik lezatnya makanan. Penerbit Andi Offset : Yogyakarta. 